\title{
Chronic pain associated with penile prostheses may persist despite revision or explantation
}

\author{
Jeffrey D. Campbell, $M D^{1,2}$; Ernest Pang Chan, $M D^{1}$; Andrew Di Pierdominico, $M D^{1}$; Serkan Karakus, $M D^{2}$; \\ Bruce Trock, MD2; Gerald B. Brock, MD'; Arthur L. Burnett, $M D^{2}$
}

'Department of Surgery, Division of Urology, Schulich School of Medicine and Dentistry, Western University, London, ON, Canada; ${ }^{2}$ The James Buchanan Brady Urological Institute and Department of Urology, the Johns Hopkins School of Medicine, Baltimore, MD, United States

Cite as: Campbell JD, Chan EP, Di Pierdominico A, et al. Chronic pain associated with penile prostheses may persist despite revision or explantation. Can Urol Assoc J 2022;16(2):42-6. http://dx.doi. $\operatorname{org} / 10.5489 /$ cuaj.7391

Published online September 24, 2021

See related commentary on page 47

\section{Abstract}

Introduction: Inflatable penile prosthesis (IPP) implantation is the gold standard treatment for medically refractory erectile dysfunction. New chronic pain after IPP implantation is rarely discussed and the optimal treatment is unclear. We evaluated whether IPP re-operation for a primary indication of chronic pain improves patients' symptoms. Our secondary aim was to explore factors associated with resolution or persistence of pain after IPP reoperation. Methods: We conducted a retrospective analysis of 315 patients who had an IPP revision or explantation at two high-volume prosthetic centers between May 2007 and May 2017. We excluded patients who had device malfunction, pain for $<2$ months, pain associated with infection or erosion, and patients without long-term followup data. Persistent pain was diagnosed based on patient self-report.

Results: A total of 31 patients met our criteria for having undergone a surgical revision $(n=18)$ or explantation $(n=13)$ for pain relief. Eighteen (58\%) patients had persistent pain despite surgical intervention. Only patients who had pain secondary to a device malposition improved after re-operation $(n=13)$. A prior diagnosis of a chronic pain syndrome was associated with persistent pain despite intervention. Pain improvement was not associated with age, comorbid conditions, duration of implant, or the number of surgical revisions performed.

Conclusions: Surgical intervention for chronic penile prosthesis pain is unlikely to relieve symptoms, particularly for patients with chronic pain disorders. Patients should be counselled that IPP reoperative procedures as a treatment for pain should be avoided unless the device is identified to be malpositioned, and consideration of alternative therapeutic options may be more beneficial.

\section{Introduction}

The inflatable penile prosthesis (IPP) has been used for the treatment of erectile dysfunction (ED) for more than 40 years. ${ }^{1}$ Innovations in the IPP have improved its durability, ${ }^{2}$ lowered infection rates, ${ }^{3}$ and resulted in a high patient and partner satisfaction rate. ${ }^{4}$ Given this, IPP is regarded as the gold standard treatment for medically refractory ED. ${ }^{5}$

Postoperative pain is expected after IPP implantation, with an anticipated duration of up to six weeks. Chronic pain post-IPP implantation was first defined in the literature as pain persisting for $>2$ months post-surgery. ${ }^{6}$ A subset of chronic penile prosthesis pain may be analogous to chronic post-surgical pain (CPSP), which is defined by pain of a least two months' duration developing after a surgical procedure in the absence of an identifiable cause (e.g., malposition). ${ }^{7}$ The literature pertaining to CPSP emphasizes prevention of postoperative pain and application of nonoperative interventions for established pain. ${ }^{7}$

Patients with chronic penile prosthesis pain represent a unique cohort. Some may have pain related to device malposition and, therefore, have an anatomical cause for pain resulting in exclusion from categorization as CPSP. Previous reports have documented an improvement in chronic pain after surgically addressing malposition of the device, particularly cylinder buckling or reservoir migration. ${ }^{8,9}$ To our knowledge, these observations have not been replicated in a larger case series.

Here, we review a case series of patients who underwent IPP re-operation for the indication of chronic penile prosthesis pain. We hypothesized that de novo chronic pain after penile prosthesis implantation is not correctable with surgical revision unless there is a device malposition. Furthermore, we sought to explore risk factors for persistent chronic pain after IPP re-operation procedures. 


\section{Methods}

\section{Study design}

Institutional ethics and review board approval was obtained for this study from both Johns Hopkins Medical Institution (IRB00128139) and Western University (REDA:110711). A retrospective review of 315 patients who underwent an IPP re-operation (revision or explantation) at these institutions between May 2007 and May 2017 was performed. All patients who required IPP re-operation for a new diagnosis of chronic penile prosthesis pain were identified. Chronic penile prosthesis pain was defined as new penile, pelvic, or scrotal content discomfort persisting longer than two months after IPP implantation. Patients who required re-operation due to erosion or infection were excluded, as were those who did not have long-term followup data available.

\section{Outcome measures}

Patient charts were reviewed for demographic information and medical comorbidities, including age of first IPP implantation, race, Charlson comorbidity index $(\mathrm{CCl})$, body mass index (BMI), history of mental health disorders, and history of chronic pain disorders. Patients who requested surgery for a diagnosis of de novo chronic penile prosthesis pain were further analyzed for history of opioid use, smoking history, duration of pain, location of pain, and whether their pain improved after revision. Patients whose pain improved were compared to patients who had persistent pain despite surgical intervention. Pain resolution was defined by a subjective report at the 6-8-week followup after re-operation.

\section{Statistical analysis}

Statistical analysis was performed using Graph Pad Prism 7 (San Diego, CA, U.S.). Continuous variables were compared using the Wilcoxon rank sum test, and categorical variables were compared using Fisher's exact test or binomial logistic regression where applicable. Statistical significance was set at $\mathrm{p}<0.05$.

\section{Perioperative and early postsurgical management}

All patients underwent IPP reoperation at either The Johns Hopkins Hospital, Baltimore, MD (U.S.) or St. Joseph's Healthcare, London, ON (Canada). Patients received a perioperative antibiotic regimen of intravenous vancomycin and gentamicin, followed by a two-week course of oral antibiotics (typically fluoroquinolone). Early postoperative pain $(<2$ months) was managed by a trial of antibiotics for possible infection or non-steroidal anti-inflammatory drugs (NSAIDs) for inflammation at the discretion of the primary surgeon. Malposition was determined preoperatively by physical examination. No imaging protocols were used for routine assessment of device malposition.

\section{Results}

A total of 315 patients underwent IPP surgical revision or explantation procedures (Fig. 1). Of these patients, 81 were excluded from the study for a diagnosis of infection or erosion requiring emergent intervention. Two hundred and three patients required re-operation for indications other than de novo chronic pain. The most common reason for re-operation was mechanical failure. A total of 40 patients required re-operation surgery for pain related to their IPP; however, nine of these patients were excluded because their pain was present for less than two months after initial IPP surgery or they had no long-term data. All patients undergoing re-operation for treatment of their pain had a three-piece inflatable device in situ.

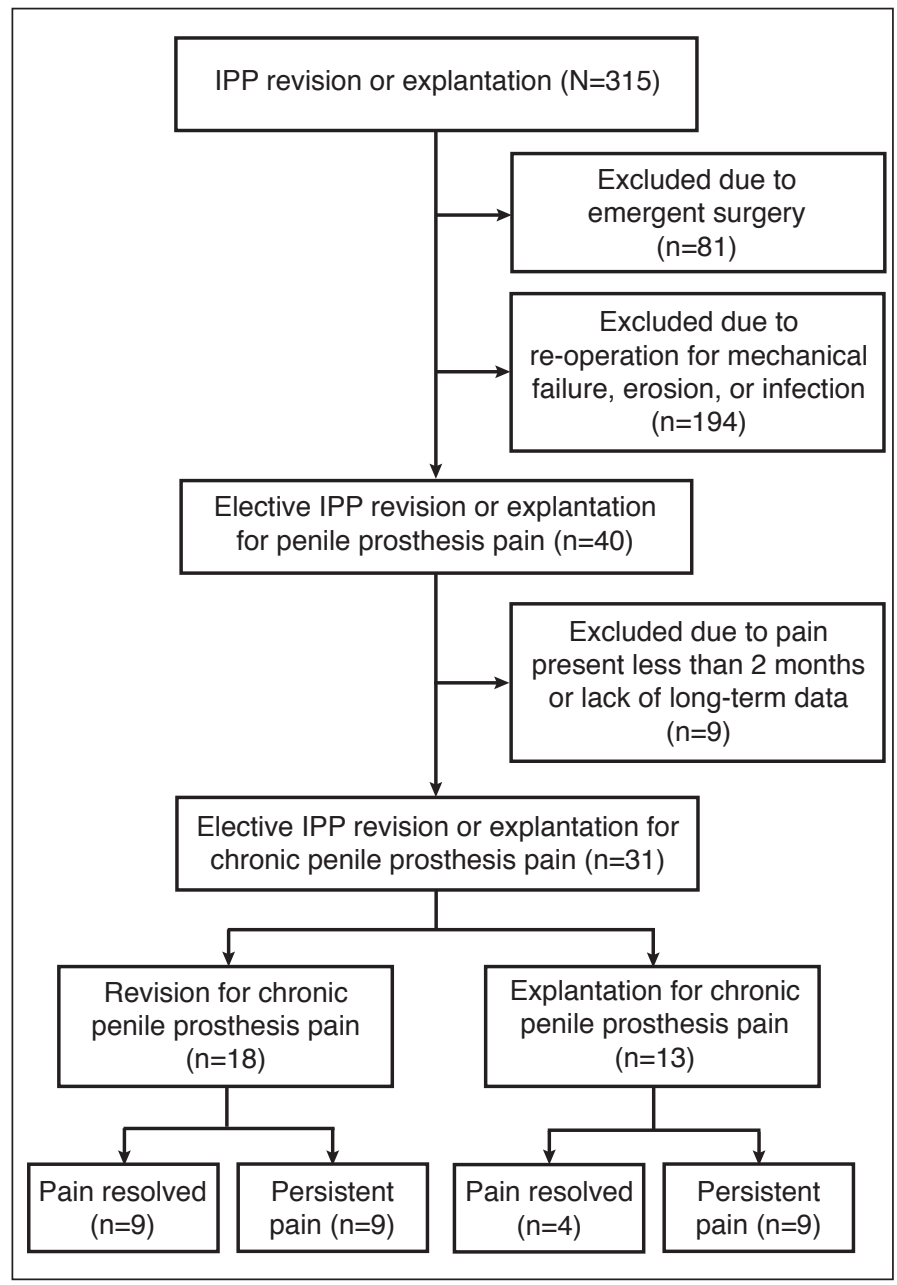

Fig. 1. Flow diagram of inclusion criteria for chronic penile prosthesis pain intervention and postoperative pain outcomes. IPP: inflatable penile prosthesis. 


\begin{tabular}{|c|c|c|c|}
\hline Variable & $\begin{array}{l}\text { Pain resolved } \\
\qquad(n=13)\end{array}$ & $\begin{array}{l}\text { Persistent pain } \\
(n=18)\end{array}$ & p \\
\hline $\begin{array}{l}\text { Age at first IPP (years, } \\
\text { IQR) }\end{array}$ & $58(47-76.5)$ & $52.5(43-62)$ & 0.74 \\
\hline $\begin{array}{l}\text { Age at revision (years, } \\
\text { IQR) }\end{array}$ & $59(46-76)$ & 59 (53-70.5) & 1.00 \\
\hline BMI $\left(\mathrm{kg} / \mathrm{m}^{2}, \mathrm{IQR}\right)$ & $31.5(28.7-33.1)$ & $32.3(27.6-34.3)$ & 0.84 \\
\hline $\mathrm{CCl}$ & 2.0 & 2.5 & 0.40 \\
\hline Smoker (n, \%) & $3(23.1 \%)$ & $5(27.8 \%)$ & 1.00 \\
\hline $\begin{array}{l}\text { Radical prostatectomy } \\
(\mathrm{n}, \%)\end{array}$ & $3(23.1 \%)$ & 7 (38.9\%) & 0.45 \\
\hline Hypertension (n, \%) & $6(46.2 \%)$ & $11(61 \%)$ & 0.48 \\
\hline Diabetes mellitus ( $n, \%$ ) & $4(30.8 \%)$ & $5(27.8 \%)$ & 1.00 \\
\hline Dyslipidemia (n, \%) & $7(53.8 \%)$ & 7 (38.9\%) & 0.49 \\
\hline $\begin{array}{l}\text { History of a chronic } \\
\text { pain syndrome }(n, \%)\end{array}$ & $1(7.6 \%)$ & $8(44.4 \%)$ & 0.04 \\
\hline $\begin{array}{l}\text { History of chronic } \\
\text { opioid use }(n, \%)\end{array}$ & $1(7.6 \%)$ & $5(27.8 \%)$ & 0.34 \\
\hline $\begin{array}{l}\text { History of anxiety or } \\
\text { depression }(n, \%)\end{array}$ & $5(38.5 \%)$ & $2(11.1 \%)$ & 0.09 \\
\hline \multicolumn{4}{|c|}{$\begin{array}{l}\text { Numbers expressed as medians unless otherwise specified. BMI: body mass index; CCI: } \\
\text { Charlson comorbidity index; IPP: inflatable penile prosthesis; IQR: interquartile range. }\end{array}$} \\
\hline
\end{tabular}

Thirty-one patients were included for this study as patients who required surgical intervention (revision or explantation) for a new diagnosis of chronic penile prosthesis pain. The decision to perform IPP revision vs. surgical explantation was based on shared decision-making and patient preference. If the patient preferred to have the device component repositioned in an attempt to improve mechanical function, they underwent revision surgery. Device component revision or concurrent explantation and re-implantation were performed for revision surgeries. If the patient no longer desired a penile prosthesis, explantation of all device components was performed.

Eighteen (58\%) patients had persistent pain despite a surgical intervention, leaving only $13(42 \%)$ patients who had improvement in their pain after intervention (Table 1). Most patients having improvement in their pain localized pain to their penis $(84.6 \%)$, whereas those with persistent pain had pelvic $(25 \%)$ or scrotal $(38 \%)$ localizations. Of re-operative procedures, $18(58.1 \%)$ were revisions and 13 (41.9\%) were explantations (Table 2)

There was no statistical significance between group demographics, including age of first IPP, age of revision surgery, total number of IPP surgical procedures, type of re-operation (revision vs. explantation) (Tables 1, 2). In addition, there was no difference between race, $\mathrm{BMI}, \mathrm{CCl}$, prostate cancer treatment, smoking habits, rates of diabetes mellitus (DM), or other comorbidities. Patients with a prior diagnosis of a chronic pain syndrome were more likely to have persistent pain $(p<0.05)$ after their revision surgery. There was no

\begin{tabular}{|c|c|c|c|}
\hline Variable & $\begin{array}{l}\text { Pain resolved } \\
\quad(n=13)\end{array}$ & $\begin{array}{c}\text { Persistent } \\
\text { pain }(n=18)\end{array}$ & $\mathbf{p}$ \\
\hline Total \# of IPP surgeries & 2 & 2 & 0.43 \\
\hline $\begin{array}{l}\text { Duration of pain (mean } \\
\text { years) }\end{array}$ & 0.7 & 0.8 & 0.76 \\
\hline \multicolumn{4}{|l|}{ Location of pain (n, \%) } \\
\hline Scrotal/testis & $2(15.4 \%)$ & $6(38 \%)$ & $<0.01$ \\
\hline Pelvic & 0 & $4(25 \%)$ & \\
\hline Penile & $11(84.6 \%)$ & $6(38 \%)$ & \\
\hline $\begin{array}{l}\text { Pain is associated with } \\
\text { device malposition (n, \%) }\end{array}$ & $13(100 \%)$ & $5(27.8 \%)$ & $<0.001$ \\
\hline \multicolumn{4}{|l|}{ Type of re-operation (n, \%) } \\
\hline Revision & $9(69.2 \%)$ & $9(50 \%)$ & 0.462 \\
\hline Explant & $4(30.8 \%)$ & $9(50 \%)$ & \\
\hline
\end{tabular}

Numbers expressed as medians unless otherwise specified. IPP: inflatable penile prosthesis.

statistically significant association with preoperative use of opioids or a history of mental health diagnoses (Table 1).

Importantly, all patients who had pain resolution had pain associated with a malposition of their device, which was most commonly identified with the valve pump (38.4\%), followed by the cylinders (26\%). No patients had pain related to the position of the reservoir. Five patients had persistent pain after intervention despite preoperatively identified device malposition; two of these patients had a previous diagnosis of chronic pain syndrome and another two had a history of prior opioid use (Table 1).

\section{Discussion}

In this series of 31 patients who underwent re-operation for de novo chronic penile prosthesis pain, all patients with pain resolution had malposition of their device. When reoperation was performed for all patients with chronic penile prosthesis pain, we observed resolution in only $42 \%$. We infer that patients with chronic penile prosthesis pain may be categorized into either those with an anatomic, and therefore surgically correctable, etiology of their pain or those with a non-identifiable pain etiology analogous to CPSP.The best precedent for our data is that of a report of five patients with persistent ( $>2$ months) penile pain post-IPP implantation by Moncada et al. ${ }^{6}$ In their series, all patients had confirmation of device malposition with MRI demonstrating cylinder buckling. All patients had resolution of their pain following device revision. In our series, we emphasize that the majority of patients $(84.6 \%)$ with improvement in their pain post-revision/explant had localized their pain to their penis. In this context, we propose persistent penile pain as a pertinent finding on history and one that may be suggestive of device malposition. 
The location of pain was not a reliable predictor of which device component was malpositioned in our series. Penile pain was found to be related to malpositioned cylinders $(26 \%)$ or valve pumps $(38 \%)$. Surgical correction of the affected component(s) resulted in resolution of chronic postsurgical pain. It is important to evaluate all device components during assessment of chronic penile prosthesis pain.

It is not known what proportion of men will develop chronic pain post-IPP insertion. The Food and Drug Administration Manufacturer and User Facility Device Experience Database identified "pain" as the cause of device failure in 5\% of AMS 700 devices and $2 \%$ of Coloplast Titan devices, ${ }^{10}$ although it is unclear what proportion of patients met the definition of chronic pain.

In this series, 31 patients who underwent IPP surgical intervention for de novo chronic pain represented $10 \%$ of all IPP re-operation procedures performed during the study period. There is limited published data available to compare this result. In two different series of 397 and 240 device insertions, respectively, only one patient in each required subsequent surgery for chronic pain; however, this was not a primary study endpoint and was possibly under-reported..$^{11,12}$ Contemporary publications of IPP revision do not always report the number of patients who underwent surgery for the indication of pain. ${ }^{13}$ Compared to the existing literature, we observed a high proportion of revisions for pain in our cohort, which is likely explained by the high volume of referrals for complex clinical presentations or the rigorous monitoring of patient recovery postoperatively.

CPSP is associated with many risk factors, including the existence of preoperative pain, younger age, genetic susceptibility, psychological traits, longer duration of surgery, and the severity of postoperative pain. ${ }^{14}$ Consistent with this, we identified that patients with a pre-existing diagnosis of a chronic pain syndrome were more likely to have persistent pain after IPP reoperation. CPSP may occur after other genito-pelvic procedures, including vasectomy $(0-37 \%)$, radical prostatectomy $(35 \%)$, and hysterectomy $(25 \%) .{ }^{15}$ The pathophysiology of chronic pain is complex and while not all patients with CPSP have neuropathic pain, nerve injury may be implicated in the development of CPSP. Inflammatory and immune reactions that take place after damage to nerve axons may result in a pathological release of neurotransmitters locally and centrally to produce hypersensitivity, ectopic neuronal activity, and central sensitization. ${ }^{16}$ Given the similarities in definition between chronic penile prosthesis pain and CPSP, the entities may share a similar pathophysiology and we propose that non-responders to device revision/explantation have a condition analogous to CPSP.

Multimodal analgesia pathways have been described to manage early postoperative IPP pain to good effect. ${ }^{17,18}$ The established neuropathic component of CPSP may respond to gabapentinoids, tricyclic antidepressants, or serotonin- norepinephrine reuptake inhibitors. ${ }^{19}$ Non-pharmacological treatments, such as cognitive behavioral therapy and physical therapies (e.g., massage, physiotherapy, acupuncture, physical exercise), may have a role as well. ${ }^{20,21}$ Given the complexity of CPSP, we recommend early referral of these patients to a pain specialist.

Our analysis did not include patients with chronic penile prosthesis pain whose symptoms resolved with conservative management. At our center, most patients with chronic penile prosthesis pain are initially treated with a course of long-acting NSAIDs, a pelvic floor physiotherapy regimen, and an extended course of antibiotics as indicated. Anecdotally, most patients notice improvement with physiotherapy after 6-9 months. There is a paucity of evidence to support the use of these adjuncts in the setting of chronic penile prosthesis pain. The patients included in our study had pain severe enough that they were either refractory to or unwilling to comply with conservative measures and as a result underwent surgical re-operation.

We caution against the operative management of patients with chronic penile prosthesis pain who do not have evidence of device malposition, as this was a requisite for improvement of pain in this study. Patients with history of chronic pain syndromes should receive thorough preoperative counselling regarding the risk of persistent pain despite re-operation. Serious causes of pos-operative pain (e.g., infection, malignancy, device herniation, osteitis pubis) should also be investigated when clinical suspicion exists. We have incorporated these suggestions into an algorithm for the management of pain post-IPP insertion (Fig. 2).

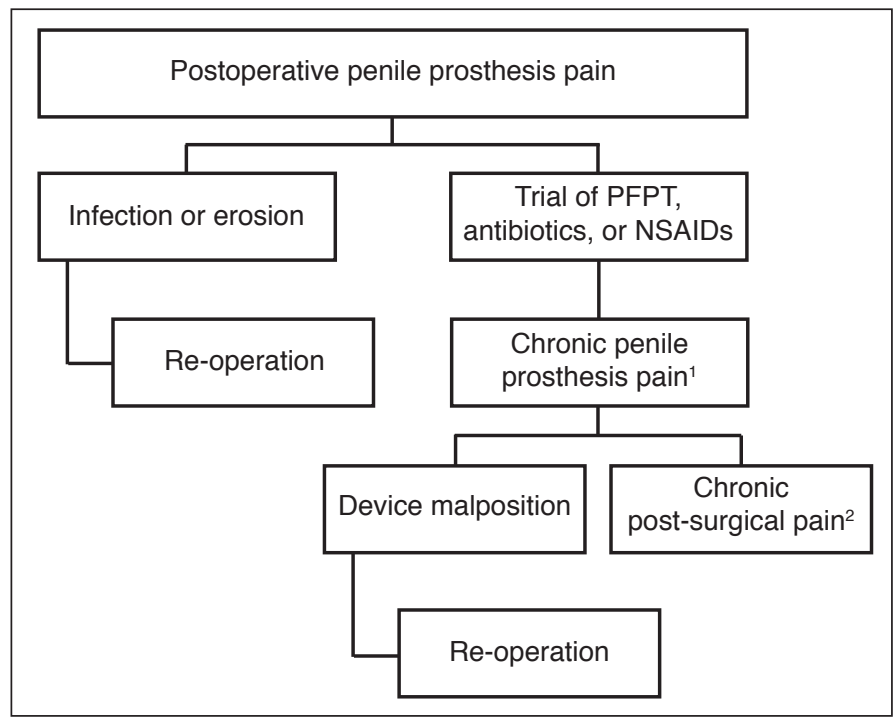

Fig. 2. A proposed algorithm for the management of chronic pain after placement of an inflatable penile prosthesis (IPP). 'Pain associated with penile prosthesis last longer than 2 months following primary implantation. ${ }^{2}$ Chronic post-surgical pain is a diagnosis of exclusion, assess for other causes (infection, erosion, etc.) if clinically suspected. NSAIDs: non-steroidal antiinflammatory drugs; PFPT; pelvic floor physiotherapy. 
Our study is limited by the retrospective collection of data, which is subject to inherent bias, as well as unavailability of some medical records. Pain was not reported on a validated scale. The study design did not include a control group, which precludes making definitive conclusions about the relative efficacy of pain resolution after surgical reoperation. Furthermore, the long-term outcomes of those patients with persistent pain despite re-operation was not available, and we cannot discern whether re-operation may have resulted in a delayed benefit. Despite these considerations, our findings are informative in terms of describing outcomes of surgery for chronic penile prosthesis pain. Our data is also consistent with the limited existing literature that patients with penile pain from penile prosthesis malposition may benefit from corrective surgery.

\section{Conclusions}

This study indicates that surgical intervention for chronic penile prosthesis pain is unlikely to relieve patient symptoms unless the existing penile prosthesis is malpositioned. Patients with a history of a chronic pain syndrome are more likely to have persistent pain after re-operation. Patients should be counselled that surgical procedures as a treatment for pain should be avoided and consideration of alternative therapeutic options may be more beneficial.

Competing interests: Dr. Brock has been an advisory board member for and holds investments in Boston Scientific. Dr. Burnett been an advisory board member for UroMissionsWorks Inc.; has received payment for consultant work/article publication/steering committee participation for clinical trials from Astellas, Boston Scientific, and Novartis; has received grants/honoraria from Boston Scientific and Endo Pharmaceuticals; and has participated in clinical trials on urinary incontinence, prostate cancer monitoring, and erectile dysfunction supported by Boston Scientific; Myriad, and Futura Medical, respectively. The remaining authors do not report any competing personal or financial interests related to this work.

This paper has been peer-reviewed.

\section{References}

1. Scott $F B$, Bradley WE, Timm GW. Management of erectile impotence. Use of implantable inflatable prosthesis. Urology 1973;2:80-2. https://doi.org/10.1016/0090-4295(73)90224-0
2. Wilson SK, Delk JR, Salem EA, et al. Long-term survival of inflatable penile prostheses: Single surgical group experience with 2384 first-ime implants spanning two decades. J Sex Med 2007;4:1074-9. https://doi.org/10.1111/j.1743-6109.2007.00540.x

3. Trost LW, McCaslin R, Linder B, et al. Long-term outcomes of penile prostheses for the treatment of erectile dysfunction. Expert Rev Med Devices 2013;10:353-66. https://doi.org/10.1586/erd.12.92

4. Lledó-García E, Jara-Rascón J, Moncada lribarren I, et al. Penile prosthesis first and replacement surgeries: Analysis of patient and partner satisfaction. J Sex Med 2015;12:1646-53. https://doi.org/10.1111/ ism.12932

5. Burnett AL, Nehra A, Breau RH, et al. Erectile dysfunction: AUA Guideline. J Urol 2018;200:633-41. https://doi.org/10.1016/i.juro.2018.05.004

6. Moncada I, Hernández C, Jara J, et al. Buckling of cylinders may cause prolonged penile pain after prosthesis implantation: A case control study using magnetic resonance imaging of the penis. J Urol 1998;160:67-71. https://doi.org/10.1016/S0022-5347(01)63033-7

7. Macrae WA. Chronic post-surgical pain: 10 years on. Br J Anaesth 2008;101:77-86. https://doi.org/10.1093/bja/aen099

8. Hernandez JC, Trost L, Kohler T, et al. Emerging complications following alternative reservoir placement during inflatable penile prosthesis placement: A 5-year multi-institutional experience. J Urol 2019;201:5816. https://doi.org/10.1016/i.juro.2018.10.013

9. Agrawal V, Rickards D, Ralph DJ. Ejaculatory pain as a result of inflatable penile prosthesis reservoir compressing a seminal vesicle. Urology 2006;68:888. https://doi.org/10.1016/i.urology.2006.05.002

10. Hagedorn JC, Osbun N, Lundy $\mathrm{S}$, et al. Inflatable penile prosthesis failure and complications: review of a national database. 2015. J Urol 193:4Se43-4. https://doi.org/10.1016/i.juro.2015.02.193

11. Kim DS, Yang KM, Chung HJ, et al. AMS 700CX/CXM inflatable penile prosthesis has high mechanical reliability at long-term followup. J Sex Med 2010;7:2602-27. https://doi.org/10.1111/i.17436109.2010.01801.x

12. Kohler TS, Moore A, Ring J. A contemporary series of penile implant complications occurring at a training institution. J Urol 2016;13:S68. https://doi.org/10.1016/i.jsxm.2016.02.151

13. Grewal S, Vetter J, Brandes SB, et al. A population-based analysis of contemporary rates of reoperation for penile prosthesis procedures. Urology 2014;84:112-6. https://doi.org/10.1016/i.urology.2014.02.028

14. Perkins FM, Kehlet H. Chronic pain as an outcome of surgery. A review of predictive factors. Anesthesiology 2000;93:1123-33. https://doi.org/10.1097/00000542-200010000-00038

15. Visser EJ. Chronic post-surgical pain: Epidemiology and clinical implications for acute pain management. Acute Pain 2006;8:73-81. https://doi.org/10.1016/i.acpain.2006.05.002

16. Searle RD, Simpson KH. Chronic post-surgical pain. Continu Educ Anaesth Crit Care Pain 2010;10:12-4. https://doi.org/10.1093/biaceaccp/mkp041

17. Tong CMC, Lucas J, Shah A, et al. Novel multimodal analgesia protocol significantly decreases opioid requirements in inflatable penile prosthesis patients. J Sex Med 2018;15:1187-94. https://doi.org/10.1016/i.jsxm.2018.05.017

18. Lucas J, Gross $M$, Yafi F, et al. A multi-institutional assessment of multimodal analgesia in penile implant recipients demonstrates dramatic reduction in pain scores and narcotic usage. J Sex Med 2019;17:518-25. https://doi.org/10.1016/i.jsxm.2019.11.267

19. Glare P, Aubrey KR, Myles PS. Transition from acute to chronic pain after surgery. Lancet 2019;393:153746. https://doi.org/10.1016/S0140-6736(19)30352-6

20. McBeth J, Prescott G, Scotland G, et al. Cognitive behavior therapy, exercise, or both for treating chronic widespread pain. Arch Intern Med 2012;172:48-57. https://doi.org/10.1001/archinternmed.2011.555

21. Thapa P, Euasobhon P. Chronic postsurgical pain: current evidence for prevention and management. Korean J Pain 2018:31:155-73. https://doi.org/10.3344/kip.2018.31.3.155

Correspondence: Dr. Emest Pang Chan, Department of Surgery, Division of Urology, Schulich School of Medicine and Dentistry, Western University, London, ON, Canada; ernest.kc.chan@gmail.com 